\title{
DAMPAK TALENT MANAGEMENT TERHADAP EMPLOYEE RETENTION PADA MILLENIALS WORKFORCE
}

\author{
Murti Sumarni \\ Universitas PGRI Yogyakarta \\ Jl. PGRI 1 Sonosewu No. 117, Yogyakarta \\ omamurti53@gmail.com
}

\begin{abstract}
The aim of this research was focused to determine the impact of Talent Management to Employee Retention in the case of Millenials Workforce. Previous research found that Human Resource Development Manager were dealing with Y Generation who had a unique work ethic, so it needed a different retention of employee. The reliability and validity test was conducted to 30 respondents and the result showed that all questions item were proven valid and reliable to be used in further research analysis. Populations in this research were the millennial employees. Questionnaire was used to collect the data in the amount of 60 respondents. This research used SPSS to analyze and the result of the linier regression analysis indicated that the Talent Management had a significant effect to Millenials Workforce Employee Retention.
\end{abstract}

Keyword: Talent Management, Millenials Workforce, Employee Retention

\section{Latar Belakang}

Pada tahun 2018 revolusi dalam
bidang industri diperkirakan telah mencapai yang keempat. Revolusi Industri di Indonesia yang pertama adalah pada jaman Hindia-Belanda, ditandai dengan adanya steam engine atau mesin uap, kedua adalah pada saat otomotif mulai berkembang di Indonesia, dan yang ketiga adalah adanya otomatisasi sistem serta globalisasi. Revolusi Industri 4.0 direspon oleh Pemerintah Indonesia dengan meresmikan peta jalan atau roadmap yang disebut Making Indonesia 4.0, termasuk peluncuran bidang-bidang yang menjadi fokus pembangunan industri, yaitu makanan dan minuman, elektronik, otomotif, tekstil, footwear, dan kimia.

Revolusi ini dimulai sejak munculnya teknologi internet pada tahun 1990-an, dan semakin berkembang hingga saat ini, dan akhirnya muncullah ekonomi digital yang membuat lingkungan bisnis menjadi semakin dinamis karena akses terhadap informasi juga semakin mudah (https://finance.detik.com, diakses pada tanggal 4 April 2018).

Tentunya Revolusi Industri 4.0 ini memberikan dampak yang sangat luas, utamanya bagi masyarakat dan pengelola bisnis. Pengelola bisnis dituntut untuk mampu mengelola Sumber Daya Manusia (SDM), sebagai salah satu komponen utama dalam organisasi di tengah-tengah perkembangan industri yang sangat cepat dan penuh persaingan. Pengelolaan SDM menjadi fokus pemikiran bagi manager karena penanganan SDM yang tepat akan mampu meminimalkan Turnover yang sering menjadi masalah bagi manager pada kurun waktu satu dasawarsa terakhir ini.

Pada realitanya perekonomian telah dikendalikan oleh pengetahuan, pengetahuan global, dan modal intelektual. Modal intelektual menjadi sumber yang penting bagi organisasi untuk mencapai keuntungan kompetitifnya (Markos dan Sridevi, 2010), oleh karenanya talent management bukanlah menjadi suatu hal yang berlebihan untuk dilakukan 
mengingat dampaknya bagi peningkatan produktivitas, profitabilitas, dan pertumbuhan perusahaan yang stabil dari waktu ke waktu.

Talent management adalah suatu upaya dalam pengelolaan SDM demi menarik sekaligus mempertahankan talented people atau karyawan-karyawan yang berbakat sekaligus terdidik di perusahaan. Dilema perusahaan pada saat ini adalah dalam hal memformulasikan strategi dengan tujuan untuk menemukan talented worker dan melakukan retention untuk menggantikan Baby Boomers yang memasuki masa pensiun pada angkatan kerja saat ini (Oladapo, 2014).

Pekerja-pekerja yang berpendidikan sekaligus berbakat sangat dibutuhkan untuk efisiensi dan efektivitas organisasi. Kompetensi serta kualitas pekerja seperti ini dapat diperoleh dari Generasi Y, yang sering dikenal dengan millennials, dengan karakter-karakter unik seperti penguasaan yang tinggi terhadap teknologi informasi dan komunikasi, multitasking, kemampuan yang baik dalam bekerjasama, sekaligus kepercayaan diri yang sangat tinggi.

Ruang lingkup talent management terdiri dari lima kategori, yaitu rekruitmen untuk menentukan karyawan yang tepat, manajemen kinerja untuk menilai pekerjaan yang dihasilkan, ketepatan waktu rencana suksesi, ketepatan pemilihan tempat pelatihan dan pengembangan, serta retensi untuk menentukan kemampuan dan keahlian secara tepat melalui proses yang tergambar dalam Tabel 1 berikut ini (Oladapo, 2014):

Tabel 1. Proses Talent Management

$\begin{array}{cl}\begin{array}{cl}\text { ORGANIZATIONAL } \\ \text { ACHIEVEMENTS }\end{array} & \text { EMPLOYEE } \\ \text { Recruitment } & \begin{array}{l}\text { Right } \\ \text { employees }\end{array} \\ \text { Performance } & \begin{array}{l}\text { Performing the } \\ \text { Management }\end{array} \\ \text { right job }\end{array}$

\begin{tabular}{|ll|}
\hline Succession Planning & Right time \\
\hline $\begin{array}{l}\text { Training and } \\
\text { Development }\end{array}$ & Right place \\
\hline Retention & $\begin{array}{l}\text { Right skills and } \\
\text { ability }\end{array}$ \\
\hline
\end{tabular}

Berdasarkan tabel tersebut terlihat bahwasanya tiap komponen memiliki peran masing-masing, akan tetapi harus tetap dilihat sebagai satu paket utuh dalam penerapannya demi tercapainya keunggulan kompetitif perusahaan melalui pengelolaan SDM.

Pada lebih dari enam puluh tahun terakhir terdapat tiga generasi, yaitu Baby Boomers Generation, Generation X, dan Generation $\mathrm{Y}$, yang sering dikenal dengan sebutan Millenials. Ketika Generasi Y ini masuk dalam dunia kerja, maka perilaku organisasi ikut berubah untuk menyesuaikan diri dengan adanya generasi baru tersebut, sehingga ketiga generasi tersebut dapat hidup berdampingan (Kaifi, et.al., 2012).

Baby Boomers adalah generasi yang lahir sebelum tahun 1965. Mereka membangun kehidupan setelah adanya Perang Dunia II, dicirikan dengan memiliki banyak anak, menganggap teknologi sebagai 'artefak', sering fokus pada hobinya, menyukai keseimbangan dalam hidup, dan masih memiliki banyak pilihan dalam pekerjaan (Rosenberg, 2009). Sedangkan Generation $X$ adalah generasi yang lahir antara tahun 1965-1980 (Kane, 2012), dicirikan dengan sangat individualis, adaptif, tidak menyukai formalitas, fokus pada outcome daripada proses karena kesenjangan dalam kemampuan kerja dan tidak sabar, serta suka berterus terang (Salahuddin, 2010).

Generasi yang belum lama berada di dunia kerja adalah Generasi $\mathrm{Y}$ atau Millenials yaitu generasi yang lahir setelah tahun 1980. Generasi ini sangat terbuka, literasi terhadap teknologi informasi dan komunikasi tinggi, sehingga karyawan 
tipikal ini menjadi sebuah aset tersendiri bagi perusahaan karena sangat familiar dengan teknologi digital. Generasi ini skeptis terhadap komitmen jangka panjang, lebih menyukai pekerjaan dengan fleksibilitas tinggi, suka bekerja dengan tim, namun terkadang overconfident. Manager dari generasi ini memiliki lima nilai yaitu keamanan keluarga, kesehatan, kebebasan, penghargaan terhadap pribadinya, dan persahabatan yang sejati. Meskipun millenials memiliki keahlian tinggi dalam teknologi serta kemampuan multitasking, sayangnya generasi ini sangat kurang dalam hal kemampuan berkomunikasi secara oral, written, maupun secara interpersonal.

Dalam penelitian ini, talent management yang dimaksud adalah yang dilakukan terhadap millenials karena tentunya dengan beberapa karakter unik tersebut, memberikan suatu perbedaan treatment dalam retention bagi millenials workforce. Misalnya saja dengan karekter yang sangat terbuka, bebas, dan sangat sosial maka attractive treatment dengan menggunakan reward uang sudah bukan menjadi daya tarik utama millenials. Di sisi lain, punishment bisa saja justru menjadikan turunnya produktivitas yang akan berpengaruh juga pada job satisfaction dan organizational commitment.

\section{Employee Retention yang}

didefinisikan sebagai kemampuan perusahaan untuk mempertahankan karyawan potensial yang dimiliki perusahaan untuk tetap loyal terhadap perusahaan (Sumarni, 2011). Retensi karyawan ini didasarkan pada keinginan untuk mempertahankan karyawan potensial yang memiliki kualitas dan keahlian tertentu sehingga dapat berada di perusahaan selama mungkin. Karyawan potensial merupakan modal intelektual yang sifatnya intangible sehingga tak ternilai bagi perusahaan. Selain itu, biaya yang dikeluarkan perusahaan sejak rekrutmen, pelatihan, dan pengembangan dilakukan, sangat besar, juga risiko bocornya rahasia bisnis ke perusahaan lain, utamanya pesaing, sehingga retensi karyawan menjadi hal yang mutlak dilakukan.

Berdasarkan uraian diatas, maka peneliti tertarik untuk melakukan pendalaman pada Talent Management serta pengaruhnya terhadap Employee Retention. Hal ini menjadi suatu ketertarikan bagi peneliti sebab lingkungan kerja yang menjadi tujuan peneliti adalah angkatan kerja yang dinamis, tanpa batas, terkoneksi secara digital serta tidak menyukai batasan-batasan konvensional seperti yang selama ini telah kita ketahui, yaitu angkatan kerja millennials (Millenials Workforce). Berdasarkan ketertarikan inilah maka peneliti melakukan penelitian dengan judul "Dampak Talent Management terhadap Employee Retention pada Millennials Workforce"

\section{Rumusan Masalah}

Rumusan masalah yang dapat dikemukakan berdasarkan latar belakang masalah yang telah diuraikan adalah:
"Apakah
Talent
Management
berpengaruh terhadap Employee
Retention pada Millenials Workforce?"

\section{Tujuan Penelitian}

Tujuan penelitian mengenai Dampak Talent Management terhadap Employee Retention adalah:

"Mengetahui pengaruh $\quad$ Talent
Management terhadap Employee
Retention pada Millenials Worker"

\section{Manfaat Penelitian}

Hasil penelitian ini diharapkan dapat memberikan manfaat kepada: Perusahaan, memberikan informasi empiris mengenai Talent Management dan dampaknya terhadap Employee Retention pada millenials workforce sehingga menimbulkan keterikatan secara emosional terhadap perusahaan yang dapat meminimalkan Turnover Intention; dan (2) Peneliti lain, menjadi salah satu rujukan atau referensi bagi peneliti lain, yang 
berminat melakukan penelitian dalam pengelolaan sumber daya manusia, khususnya dalam bidang Human Capital serta Talent Management.

\section{Kajian Teori}

\section{Talent Management}

Beberapa pakar mengemukakan bahwa karyawan yang bertalenta adalah karyawan yang berkompeten secara luar biasa dengan potensi yang tinggi yang secara signifikan dapat mempengaruhi kinerja organisasi dan mereka berpendapat bahwa talent management (manajemen bakat) memberikan perhatian pada individu kunci yaitu orang-orang yang berkompeten yang nantinya akan berada di puncak (Smilansky, 2005).

$$
\text { Manajemen Bakat adalah }
$$

implementasi dari strategi yang terintegrasi atau sistem yang didesain untuk meningkatkan produktivitas di tempat kerja dengan mengembangkan peningkatan proses dalam mengidentifikasi, memilih, merekrut, mengembangkan dan mempertahankan karyawan dengan memanfaatkan kemampuan dan bakat tertentu dalam memenuhi kebutuhan bisnis saat ini dan di masa depan (Lockwood, N. R., 2006). Manajemen bakat adalah cara pengelolaan bakat dalam organisasi secara efektif, perencanaan dan pengembangan suksesi di perusahaan, realisasi pengembangan diri karyawan secara maksimal dan pemanfaatan bakat secara optimal (Rampersad, 2006).

Mengidentifikasi, memilih, merekrut, mengembangkan dan mempertahankan karyawan merupakan lima fokus utama dalam manajemen bakat agar perusahaan mendapatkan keuntungan kompetitif, dan kebutuhan akan modal manusia (human capital) akan berlanjut pada manajemen bakat (Towers Perrin, 2003). Dari beberapa pendapat diatas maka dapat dikatakan bahwa manajemen bakat adalah suatu kegiatan yang bersifat strategis dalam upaya meningkatkan produktifitas melalui optimalisasi karyawan yang memiliki bakat atau bertalenta.

\section{Employee Retention}

Salah satu pusat perhatian dari perusahaan pada saat ini adalah retensi karyawan (employee retention). Retensi karyawan merupakan kemampuan perusahaan untuk mempertahankan karyawan potensial yang dimiliki perusahaan untuk tetap loyal terhadap perusahaan. Mengidentifikasi dan mempertahankan karyawan yang mempunyai talenta membuat beberapa Vice President SDM memikirkan kemungkinan dan peluang (Kaliprasad, 2006).

Tujuan dari retensi karyawan ialah untuk mempertahankan karyawan yang dianggap berkualitas, yang dimiliki oleh perusahaan, selama mungkin, karena karyawan yang berkualitas merupakan harta yang tidak tampak (intangible asset), yang tak ternilai bagi perusahaan. Retensi akan meningkat ketika karyawan ditawarkan sejumlah kompensasi dan keuntungan-keuntungan, kultur kerja yang mendukung, sekaligus adanya keseimbangan antara bekerja dan aktivitas hidup (Messmer, 2006).

Istilah retensi terkait dengan istilah perputaran (turnover) yang berarti proses ketika karyawan-karyawan meninggalkan organisasi dan harus digantikan (Mathis dan Jackson, 2009). Menurut Hasibuan (2000) pemeliharaan karyawan harus mendapat perhatian yang sungguhsungguh, dan apabila pemeliharaan karyawan kurang diperhatikan, semangat kerja, sikap dan loyalitas karyawan akan menurun.

Pemeliharaan adalah usaha mempertahankan dan atau meningkatkan kondisi fisik, mental dan sikap karyawan, agar mereka tetap loyal dan bekerja produktif untuk menunjang tercapainya tujuan perusahaan. Lebih lanjut dikatakan, bahwasanya tujuan pemeliharaan adalah sebagai berikut: 
1. Untuk meningkatkan produktivitas kerja karyawan,

2. Meningkatkan disiplin dan menurunkan absensi karyawan,

3. Meningkatkan loyalitas dan menurunkan turnover karyawan,

4. Memberikan ketenangan, keamanan, dan kesehatan karyawan,

5. Meningkatkan kesejahteraan karyawan dan keluarganya,

6. Memperbaiki kondisi fisik, mental dan sikap karyawan,

7. Mengurangi konflik serta menciptakan suasana yang harmonis,

8. Mengefektifkan pengadaan karyawan.

\section{Millenials Workers}

Selama enam puluh tahun terakhir, terdapat tiga generasi, yaitu, Generasi Baby Boomers, Generasi X, dan Generasi Y yang dikenal juga sebagai generasi millenials.

Tabel 2. Perbedaan Antar Generasi Dalam Angkatan Kerja

\begin{tabular}{ll}
\hline Generasi & $\begin{array}{l}\text { Tahun } \\
\text { Kelahiran }\end{array}$ \\
\hline Baby Boomer & $1946-1964$ \\
Generasi X & $1965-1980$ \\
Generasi Y (Generasi & Lahir Setelah \\
Millenials) & 1980 \\
\hline
\end{tabular}

Sumber: Kaifi, et.al, 2012

Generasi millenials tumbuh dalam era digital, mereka lebih familiar akan komunikasi, media dan teknologi digital. Ciri khas mereka yang lebih paham tentang IT inilah yang membuat mereka mempunyai keunggulan kompetitif dan membuat generasi millenials ini menjadi suatu aset ketika mereka bekerja dengan teknologi. Generasi millennials memasuki lingkungan kerja yang tradisional dengan muatan teknologi digital, jaringan media sosial, dan harapan-harapan yang lebih tinggi menuju lingkungan kerja yang lebih fleksibel. Generasi ini tahu apa yang mereka inginkan, lingkup pekerjaan mereka, tingkat kenyamanan dan saluran komunikasi mereka (Rai, 2012).

Sebuah studi dilakukan oleh Deloitte Consulting pada tahun 2005, berusaha untuk memahami bagaimana karakteristik generasi millennials ini dalam suatu angkatan kerja. Generasi ini mempunyai kekhususan yaitu terhubung secara digital. Penelitian yang ekstensif telah dilakukan pada generasi ini untuk memahami apa yang menandai mereka, harapan mereka, dan cara mereka terhubung dengan tempat kerja mereka.

\section{Tabel 3. Generasi Millenials di Tempat Kerja}

\begin{tabular}{l}
$\begin{array}{l}\text { Bekerja dengan baik, bersama rekan kerja } \\
\text { ataupun dalam sebuah tim }\end{array}$ \\
\hline $\begin{array}{l}\text { Kolaboratif, banyak akal, pemikir yang } \\
\text { inovatif }\end{array}$ \\
\hline Menyukai tantangan \\
\hline Selalu membuat perbedaan \\
\hline Ingin menghasilkan sesuatu yang berharga \\
\hline Keinginan menjadi pahlawan \\
\hline Tidak sabar \\
\hline Nyaman dengan kecepatan dan perubahan \\
\hline $\begin{array}{l}\text { Berkembang pada fleksibilitas serta ruang } \\
\text { untuk dijelajahi }\end{array}$ \\
\hline Bermitra baik dengan mentor \\
\hline $\begin{array}{l}\text { Berpedoman pada nilai dan mengharapkan } \\
\text { rasa hormat }\end{array}$ \\
' Sumber: Deloitte Consulting (2005) \\
YWho Are the Millennials, aka Generation \\
Y?"
\end{tabular}

Generasi millennials merupakan generasi yang fleksibel, kolaboratif, dinamis, dan menghargai keberlanjutan, serta mempunyai kemampuan untuk beradaptasi dengan lingkungan. Lingkungan tempat kerja dianggap sebagai tempat yang terlibat secara emosional dimana mereka bersosialisasi, belajar dan berkolaborasi. Ini adalah area mereka atau ruang kerja mereka yang bersifat pribadi. 
Generasi millennials juga emosional dan stylish generasi millennials lebih suka tempat kerja yang tidak berbatas, penuh warna dan terbuka dengan ruang-ruang percakapan dan zona santai tempat mereka untuk berkolaborasi, berinovasi dan berkreasi. (Generation Y and Workplace Annual Report 2010).

\section{Populasi dan Sampel}

Populasi dalam penelitian ini adalah Angkatan Kerja Millenials. Sampel dalam penelitian ini sebanyak 60 karyawan, diambil secara Random Sampling.

\section{Variabel Penelitian}

Penelitian ini melibatkan dua variabel, yaitu:

1. Talent Management $(\mathrm{TM})(\mathrm{X})$

2. Employee Retention (ER) (Y)

\section{Model Penelitian}

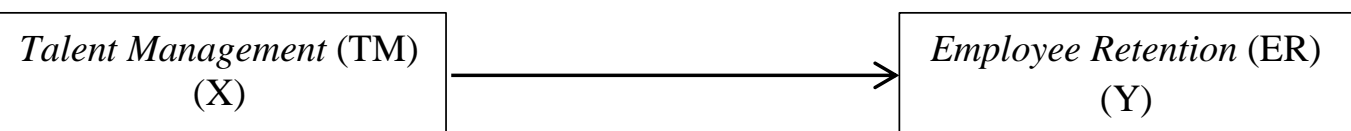

MILLENIALS WORKFORCE

\section{Hipotesis Penelitian} adalah:

Hipotesis dalam penelitian ini

Ha: Talent Management (TM) (X) berpengaruh signifikan dan positif terhadap Employee Retention (ER) (Y) pada Millenialss Workforce

\section{Sumber Data}

Data yang digunakan dalam penelitian ini adalah: (1) Data Primer, diperoleh langsung dari responden melalui kuesioner. Kuesioner berisi pertanyaanpertanyaan mengenai variabel Talent Management (TM), Employee Retention (ER); (2) Data sekunder, merupakan data mengenai objek penelitian yang diperoleh dari sumber lain, yaitu dari Literatur Buku dan berita Online.

\section{Metode Pengumpulan Data}

Metode pengumpulan data penelitian ini dilakukan dengan cara survei menggunakan kuesioner yang disebarkan kepada responden. Peneliti juga melakukan wawancara dengan responden. Seluruh variabel dalam penelitian ini diukur dengan menggunakan skala 1 sampai 4. Masingmasing alternatif jawaban akan diberi nilai numerik sebagai berikut: (1) sangat tidak setuju $=1$; (2) tidak setuju $=2$; (3) setuju $=3$; dan (4) sangat setuju $=4$.

\section{Uji Instrumen}

\section{Uji Validitas dan Reliabilitas}

Uji validitas dilakukan untuk mengetahui sejauh mana kuesioner sebagai alat ukur dapat mengukur apa yang sebenarnya ingin diukur (Cooper dan Schindler, 2003). Uji validitas digunakan untuk mengukur sah atau valid tidaknya suatu kuesioner. Suatu kuesioner dikatakan valid jika pertanyaan pada kuesioner mampu mengukur konsep yang diharapkan dan tidak mengukur hal yang lain (Sekaran, 2003). Uji validitas terdiri dari 
tiga unsur, yaitu validitas isi, validitas kriteria, dan validitas konstruk. Untuk mengukur validitas isi kuesioner, dapat menggunakan validitas tampang (face validity). Validitas konstruk menunjukkan seberapa baik hasil-hasil yang diperoleh dari penggunaan suatu pengukur sesuai dengan teori-teori yang digunakan untuk mendefinisikan suatu konstruk (Hartono, 2004).

Penelitian ini menggunakan Pearson's Correlation untuk mengukur validitas konstruk dan validitas isi dari kuesioner. Uji Reliabilitas adalah alat untuk mengukur suatu kuesioner yang merupakan indikator dari variabel atau konstruk. Suatu kuesioner dikatakan reliabel atau handal jika jawaban seseorang terhadap pernyataan adalah tanpa bias dan konsisten atau stabil dari waktu ke waktu (Sekaran, 2003). Alat uji reliabilitas yang digunakan dalam penelitian ini adalah Cronbach's Alpha untuk mengetahui kehandalan atau konsistensi alat ukur untuk mengukur. Menurut Sekaran (2003), nilai koefisien reliabilitas mendekati 1.0 adalah semakin baik: (1) < $0.6=$ buruk; (2) $0.7=$ dapat diterima; dan $(3)>0.8=$ baik.

\section{Metode Analisis Data}

Metode analisis data yang digunakan dalam penelitian ini adalah metode deskriptif dan metode inferensial. Metode deskriptif dilakukan untuk menjelaskan variabel secara mandiri, dalam artian tidak menghubungkan maupun membandingkan dengan variabel lain. Sedangkan metode inferensial dipergunakan untuk menguji hipotesis, yang dalam penelitian ini menggunakan regresi linier sederhana, dengan model sebagai berikut:

$$
\mathbf{Y}=\mathbf{a}+\mathbf{b X}+\mathbf{e}
$$

Keterangan:

$$
\begin{aligned}
& \mathrm{Y}: \text { Employee Retention } \\
& \mathrm{a}: \text { Intersep } \\
& \mathrm{b}: \text { Koefisien Regresi } \\
& \mathrm{X}: \text { Talent Management } \\
& \mathrm{E}: \text { Standar error }
\end{aligned}
$$

Uji validitas dan reliabilitas sebagai initial procedure dilakukan pada 30 (tiga puluh) responden dan menunjukkan bahwa seluruh pertanyaan adalah valid dan reliabel, dengan angka Cronbach's Alpha sebesar 0,81 sehingga dapat dikategorikan baik. Jumlah responden yang mengembalikan quesioner adalah 60 orang, dengan jenis kelamin laki-laki sebanyak 42 orang dan perempuan sebanyak 18 orang. Responden adalah pekerja yang lahir setelah tahun 1980, dari berbagai profesi seperti Pegawai Negeri Sipil, Dosen, karyawan di bidang perbankan, perkebunan, pariwisata, dan Information Technology, dengan tingkat pendidikan S1 sebanyak 19 orang dan S2 sebanyak 41 orang.

Ketika responden diberikan pertanyaan mengenai kebijakan tentang pengelolaan talent management di tempat responden bekerja, jawaban yang paling banyak muncul adalah "Ya", yaitu sebanyak 42 orang responden, sedangkan sisanya sebanyak 18 orang menjawab "Tidak". Meskipun sebanyak 18 orang menjawab "Tidak", pada dasarnya responden tersebut peduli akan adanya talent management, terbukti pada pertanyaan selanjutnya, mengenai kepedulian responden terhadap kebijakan perusahaan tentang talent management, sebanyak 48 orang responden menjawab "Ya" dan sebanyak 12 orang responden. Hal ini berarti responden memahami arti pentingnya suatu pengelolaan bakat, walaupun masih belum banyak dilakukan oleh perusahaan tempatnya bekerja.

Pada pertanyaan mengenai tingkat pengetahuan perusahaan tentang bakat/kemampuan responden, sebanyak 54 orang responden menjawab "Ya" sedangkan sisanya sebayak 6 orang responden menjawab "Tidak". Hal ini berarti meskipun pengelolaan bakat karyawan belum terlalu mengemuka melalui program-program khusus, akan tetapi perusahaan telah mampu mengidentifikasi bakat masing-masing karyawan, kemungkinan dengan melakukan analisis jabatan sesuai dengan 
kapabilitas dan bakat masing-masing karyawan.

Sedangkan hasil estimasi pada analisis regresi linier sederhana yang dilakukan menggunakan software SPSS ditunjukkan melalui tabel berikut ini:

Tabel 3. Hasil Analisis Regresi Linier Sederhana

Dampak Talent Management Terhadap Employee Retention

\begin{tabular}{|c|c|c|c|c|c|c|}
\hline $\begin{array}{c}\text { Variabel } \\
\text { Independen }\end{array}$ & $\begin{array}{c}\text { Variabel } \\
\text { Dependen }\end{array}$ & Konstanta & $\begin{array}{c}\text { Koefisien } \\
\text { Regresi }\end{array}$ & t-hitung & Sig.t & Keterangan \\
\hline $\begin{array}{c}\text { Talent } \\
\text { Management }\end{array}$ & $\begin{array}{c}\text { Employee } \\
\text { Retention }\end{array}$ & 2,270 & 0.309 & 3.210 & 0.002 & $\mathrm{H}_{\mathrm{a}}$ didukung \\
\hline
\end{tabular}

Sumber: Hasil Analisa Data dengan Menggunakan SPSS

Berdasarkan tabel tersebut maka hasil regresi linier sederhana dalam bentuk persamaan adalah sebagai berikut:

$\begin{array}{rlr}\mathbf{Y} & =\mathbf{2 , 2 7 0}+\mathbf{0 , 3 0 9 X} \\ \text { t-statistik } & =\mathbf{7 , 5 3 0} \\ \mathbf{R}^{2} & =\mathbf{3 , 2 1 0}\end{array}$

Secara statistik, variabel Talent Management berpengaruh secara signifikan terhadap Employee Retention pada Millenials Workforce. Hal tersebut ditunjukkan dengan besarnya nilai tstatistik yang diperoleh yaitu 3,210 lebih besar daripada t-tabel dengan degree of freedom $(\mathrm{df})=58$, derajat kepercayaan $5 \%$ yaitu 2,000 dengan sifat uji dua sisi. Hipotesis alternatif Talent Management berpengaruh secara signifikan terhadap Employee Retention pada Millenials Workforce mampu dibuktikan.

\section{Pembahasan}

Mengidentifikasi dan mempertahankan karyawan kunci akan selalu menjadi tantangan dalam organisasi, hal ini akan menjadi lebih sulit jika dihadapkan pada karyawan yang juga mempunyai kemampuan yang lebih. Karyawan berpendapat bahwa praktekpraktek pengelolaan Sumber Daya Manusia mempunyai tujuan dan hubungan yang positif dengan Employee Retention atau upaya-upaya untuk mempertahankan karyawan. Pada masa sekarang ini pengelolaan karyawan menjadi lebih dinamis dan kompleks, angkatan kerja millenials dengan segala karakteristiknya dengan cepat akan mengubah sudut pandang pengelolaan Sumber Daya Manusia.

Talent management yang dilakukan selama ini memang merupakan suatu hal yang strategis yang harus dilakukan oleh perusahaan, akan tetapi perusahaan perlu untuk mengubah sudut pandang dari sisi pengelolaan karyawan. Jika pada masamasa sebelumnya pengelolaan karyawan terbukti berhasil pada Generasi Baby Boomers dan Generasi $\mathrm{X}$, namun pengelolaan tersebut akan menjadi pengelolaan yang bersifat konvensional jika yang dikelola adalah Generasi $\mathrm{Y}$ atau Millenials. Manajemen Bakat (Talent Management) yang tepat akan dapat meningkatkan produktivitas dan akan membuat program Employee Retention perusahaan menjadi program yang mampu 
mengadaptasi tuntutan-tuntutan para Millenials Worker.

Millenials memasuki perusahaan tanpa melihat pengalaman dalam berkarir, mereka tidak tertarik untuk menaiki tangga karir perusahaan, menyenangkan pimpinan dan menghasilkan uang yang lebih. Mereka mempersiapkan pekerjaan lebih keras daripada generasi sebelumnya, akan tetapi mereka tidak akan menjadi produktif ketika ditempatkan dalam suatu kotak dan berharap supaya mereka akan menghasilkan kinerja selama delapan jam sehari. Dengan pendidikan yang baik, kemampuan yang tinggi dalam teknologi dan kepercayaan diri, generasi ini mengharapkan stimulasi, kolaborasi dan kompensasi. Pekerjaan perlu menjadi menarik untuk mereka dan secara sukses menarik mereka dalam pekerjaan dengan cara yang berbeda (Buchanon, 2010; Gilbert, 2011).

Employee Retention yang tepat dalam mempertahankan karyawan millenials yang bertalenta adalah memenuhi kebutuhan-kebutuhan para millenials workforce, fleksibilitas dalam bekerja perlu diciptakan sehingga akan menciptakan ruang yang luas bagi para millenials untuk meningkatkan kemampuan mereka. menciptakan suasana kerja yang kolaboratif serta memberikan otonomi kepada millenials akan membuat mereka lebih kreatif dan lebih menjadi inovatif.

\section{Kesimpulan}

Hasil penelitian menunjukkan bahwa terdapat pengaruh Talent Management terhadap Employee Retention pada Millenials Workforce. Berdasarkan hasil pengujian statistik, nilai $\mathrm{R}^{2}$ menunjukkan angka yang rendah, yaitu 0,151 , yang berarti bahwa terdapat variabel-variabel lain yang tidak terdapat dalam penelitian ini, yang berpengaruh terhadap Employee Retention. Pengelolaan karyawan millenials melalui Employee Retention mengubah sudut pandang perusahaan bahwa pengelolaan yang secara konvensional telah dijalankan selama ini harus dikoreksi dan menyesuaikan dengan perkembangan angkatan kerja yang di masa yang akan datang yang akan didominasi oleh pemanfaatan Teknologi Informasi serta tuntutan fleksibilitas dalam menjalankan pekerjaan.

\section{DAFTAR PUSTAKA}

Buchanon,L. 2010. Meet the Millenials.Inc 32(6) 166-180.

Deloitte Consulting. 2005. Who Are The Millennials (aka Generation Y)?New York: Deloitte \& Touche USA.

Gilbert,J.2011.The Millenials: The New Generation Of Employee And New Set Of Engagement Policies. The Workplace (September/October 2011).

Kaliprasad, M. 2006. The Human Factor 1: Attracting, Retaining, And Motivating Capable People. Cost Engineering, 48(6), 20-26.

Lockwood, N. R., 2006. Talent Management: Driver for Organizational Success' (SHRM Research Quarterly 2006). (Electronic) Available at: http://findarticles.com/p/articles/mi_ m3495/is_6_51/ai_n26909340/, 09.12.2011.

Markos, S. dan Sridevi, M.S. 2010. Employee Engagement: The Key to Improving

Performance. International Journal of Business and Management, 5, 89-96.

Messmer, M. 2006. Four keys to improved staff retention. Strategic Finance, 88(4), 13-14.

Oladapo, Victor. 2014. The Impact of Talent Management on Retention. 
Journal of Business Studies Quarterly Vol. 5 No. 3.

Rai, Soumi. 2012. Engaging young employees (Gen Y) in a social media dominated world - Review and Retrospection Procedia - Social and Behavioral Sciences 37 ( 2012 ) 257 $-266$.

Rampersad, Hubert K. 2006. Personal Balance Scorecard : The Way to Individual Happiness, Personal Integrity and Organization Effectiveness. United States: McGraw-Hill Education.

Salahuddin, M.M.. 2010. Generational Differences Impact On Leadership Style And Organizational Success. Journal of Diversity Management $5(2), 1-6$.

Smilansky, J. 2005. The Systematic Management of Executive Talent. London: Hydrogen.

Sumarni, Murti. 2011. Pengaruh Employee Retention Terhadap Turnover Intention dan Kinerja Karyawan. Akmenika Vol. 8 bulan Oktober.

Towers Perrin. (2003). Working today: Understanding what drives employee engagement. Retrieved August 27, 2007, from http://www.towersperring.com.

https://finance.detik.com, diakses pada tanggal 4 April 2018. 